Artigo

\title{
A RELAÇÃO PEDAGÓGICA ENTRE O PROFESSOR E O ALUNO SURDO NO ENSINO BÁSICO TENDO A LIBRAS COMO MEDIADORA
}

\author{
THE PEDAGOGICAL RELATIONSHIP BETWEEN THE TEACHER AND THE DEAF \\ STUDENT IN BASIC EDUCATION WITH LIBRAS AS A MEDIATOR
}

\section{LA RELACIÓN PEDAGÓGICA ENTRE EL PROFESOR Y EL ESTUDIANTE SORDO EN LA EDUCACIÓN BÁSICA CON LIBRAS COMO MEDIADOR}

\author{
Teresinha Ribeiro Brito \\ Ronaldo Conceição dos Santos \\ Ivonete de Souza Santos \\ Rosa Maria Lopes Freitas
}

\begin{abstract}
Resumo
O presente artigo recorre a estudos e pesquisas sobre a temática da educação inclusiva a fim de elucidar quais os obstáculos e possibilidades de superação na relação pedagógica entre o professor e o aluno surdo, em salas de aula do ensino básico es tendo a Libras como mediadora. Os argumentos foram desenvolvidos a partir de três eixos: contexto histórico e formação docente, a mediação da Libras no processo de aprendizagem e os desafios na relação pedagógica professor/aluno surdo. Trata-se de uma pesquisa bibliográfica de cunho qualitativo cuja análise sucinta da relação professor e aluno surdo no âmbito escolar evidenciou que a formação do professor em Libras é fundamental para atender às demandas educacionais do aluno e superar os obstáculos na comunicação.
\end{abstract}

\begin{abstract}
This article uses studies and research on the theme of inclusive education in order to elucidate the obstacles and possibilities of overcoming in the pedagogical relationship between the teacher and the deaf student, in classrooms of basic education having Libras as mediator. The arguments were developed from three axes: historical context and teacher training, the mediation of Libras in the learning process and the challenges in the pedagogical relationship between teacher and deaf student. It is a qualitative bibliographic research whose succinct analysis of the relationship between teacher and deaf student in the school context showed that teacher training in Libras is fundamental to meet the student's educational demands and overcome communication obstacles.
\end{abstract}

\section{Resumen}

Este artículo utiliza estudios e investigaciones sobre el tema de la educación inclusiva para dilucidar los obstáculos y las posibilidades de superación en la relación pedagógica entre el profesor y el alumno sordo, en las aulas de educación básica con Libras como mediador. Los argumentos se desarrollaron a partir de tres ejes: contexto histórico y formación del profesorado, la mediación de Libras en el proceso de aprendizaje y los desafíos en la relación pedagógica entre el profesor y el alumno sordo. Es una investigación bibliográfica cualitativa cuyo análisis sucinto de la relación entre el maestro y el alumno sordo en el contexto escolar demostró que la formación del profesorado en Libras es fundamental para satisfacer las demandas educativas del alumno y superar los obstáculos de comunicación. 
Palavras-chave: Educação Inclusiva; Surdez; Formação docente; Comunicação em Libras.

Keywords: Inclusive education; Deafness; Teacher training; Communication in Libras. Palabras claves: Educación inclusiva; Sordera Formación del profesorado; Comunicación en Libras.

\section{INTRODUÇÃO}

A Educação Inclusiva historicamente se fortaleceu através das conquistas e garantias de acesso e permanência da pessoa com deficiência ao ambiente escolar, tornando-se um marco para o ensino dessa população. Tem como ponto de partida a própria Constituição Brasileira, ao assegurar a educação como direito universal e consequentemente, a Lei Brasileira de Inclusão-LBI no 13.146/2015, baseada na Convenção sobre os direitos da pessoa com deficiência realizada pela Organização das Nações Unidas - ONU, constituindo-se como divisor no que diz respeito às matérias que tratam sobre acessibilidade e inclusão.

Em se tratando das pessoas surdas a Lei $n^{0} 10.436$, de 24 de abril de 2002 que reconheceu a Língua Brasileira de Sinais (Libras) como meio legal de comunicação e expressão, possibilitou que a pessoa surda, além de ter 0 acesso à educação básica, possa permanecer e progredir com o processo de escolaridade numa perspectiva inclusiva.

Essa Lei traz ainda uma nova perspectiva em relação à formação do professor, reforçando a importância da qualificação profissional em língua de sinais, uma vez que a "Libras deve ser priorizada em todo e qualquer espaço educativo, pois a Libras deve servir de base à apreensão de conhecimentos" (MIRANDA; FIGUEIREDO; LOBATO, 2016, p. 29).

Assim, os documentos legais supracitados preveem a garantia aos surdos do direito de estudar, juntamente com os demais alunos ouvintes, em convívio, aprendendo e participando sem nenhum tipo de discriminação, inseridos numa sala do ensino básico e recebendo os estímulos necessários para desenvolver o seu processo de aprendizagem e aos professores, 0 acesso ao conhecimento e formação adequada para atuar com a diversidade inerente ao ensino inclusivo.

Entretanto, na educação básica o ensino para pessoas surdas ainda recebe críticas distintas por parte de alguns estudiosos e profissionais que alegam que esse modelo não atende as necessidades formativas das pessoas surdas considerando a sua condição bilíngue e bi cultural. Destacam a necessidade de formação inicial e continuada que atendam a essas demandas. Nesse enfoque, esse trabalho pretende a partir da pesquisa bibliográfica, de cunho qualitativo, analisar a relação pedagógica entre o professor e o aluno surdo, em sala de aula, compreendendo os obstáculos dessa interação, e as possibilidades e superação desses a partir de práticas exercidas e mediadas pela Libras.

Através da análise dessa relação pedagógica entre o professor e o aluno surdo no ensino básico tendo a Libras como mediadora, destaque-se as possibilidades e obstáculos de comunicação utilizadas pelo professor do aluno surdo em sala de aula no processo de ensino aprendizagem e as ferramentas de interação, evidenciando os desafios a serem superados. 
Sendo assim, para uma melhor compreensão o artigo se desenvolveu no prisma de três eixos a saber: No primeiro, discorre sobre os aspectos legais da educação de surdos destacando a importância da formação docente em Libras, no segundo discute-se o processo de aprendizagem de alunos surdos tendo a Libras como mediadora e o terceiro eixo trata dos desafios para a relação pedagógica eficaz entre professor e aluno surdo em sua singularidade.

Historicamente a comunidade surda enfrentou muita discriminação sendo considerada como incapaz de aprender e se desenvolver, reforçando o processo de invisibilidade principalmente no ambiente escolar. É notório que nessa última década houve avanços importantes, impulsionando a necessidade de que a escola seja inclusiva. Porém, ainda temos o desafio de efetivar tanto 0 acesso como a permanência da pessoa surda a um ensino de qualidade. Isso requer uma formação adequada do professor para o desenvolvimento de aprendizagens significativas o que exige, necessariamente, o domínio da língua brasileira de sinais. Nessa construção, é necessário entender o percurso histórico da Educação Inclusiva com ênfase na inclusão dos alunos surdos no ensino básico, sob a ótica da formação em Libras do professor.

\title{
ASPECTOS LEGAIS E PEDAGÓGICOS DA EDUCAÇÃO DOS SURDOS E A FORMAÇÃO DOCENTE
}

A Constituição Brasileira - CF (1988) assegura que a Educação é direito de todos e esse deve ser respeitado, de forma que a escola deve promover além do acesso ao ensino, que este ocorra de forma inclusiva, de forma afirmativa às identidades das pessoas historicamente excluídas. Neste contexto, a história da educação especial/inclusiva, mais precisamente na educação dos surdos, é marcada pela exclusão, a qual impulsionou a luta pela efetivação de políticas públicas de inclusão contribuindo para o cumprimento do direito garantido pela CF. Aliás o art. 58 da Lei de diretrizes e bases da educação nacional, no 9394 de 20 de dezembro de 1996, que diz:

\begin{abstract}
Entende-se por educação especial, para os efeitos desta Lei, a modalidade de educação escolar oferecida preferencialmente na rede regular de ensino, para educandos com deficiência, transtornos globais do desenvolvimento e altas habilidades ou superdotação.
\end{abstract}

Este modelo garante uma atenção maior tangente ao atendimento educacional do aluno com deficiência tanto em infraestrutura como em profissionais capacitados, podendo ser encontrado em escolas da educação básica, e mais expressivo em escolas voltadas, especificamente, para o atendimento de uma ou mais necessidades deste público.

Por outro lado Nascimento (2008, p.12) diz que: "A educação inclusiva vai muito além de atender o aluno com necessidades educacionais especiais, pois supõe práticas educativas para todos os alunos e para o conjunto da escola". Neste caso, para uma educação inclusiva, os desafios são maiores. No entanto, a possibilidade de conceber num mesmo espaço alunos ouvintes e surdos, favorece a convivência e a aprendizagem de todos os envolvidos no espaço escolar, desta forma também é possível vislumbrar uma educação mais 
humana e social, ao passo que provoca pais, alunos, e educadores a ressignificar os espaços sociais e torna-los mais democráticos e acessíveis.

A Política Nacional de Educação Especial na perspectiva do relatório elaborado pelo Ministério da Educação no campo da Política Educação Inclusiva (2008) aponta que no Brasil, o atendimento às pessoas com deficiência teve início durante o Período Imperial, sendo criadas em 1854 o Imperial Instituto dos Meninos Cegos, atual Instituto Benjamin Constant - IBC, e em 1857, o Instituto dos Surdos Mudos, atualmente conhecido por Instituto Nacional da Educação dos Surdos - INES.

Em 1926 foi fundado o Instituto Pestalozzi que se dedicava ao atendimento das pessoas com deficiência mental, no qual em 1945 passou a realizar 0 atendimento educacional especializado às pessoas com superdotação. Já a Associação de Pais e Amigos dos Excepcionais - APAE fundada em 1954 funciona em todo território brasileiro até os dias atuais.

A década de 70 marca o início da caminhada de acesso ao ensino básico, onde alunos com deficiência passaram a ser aceitos em algumas escolas numa visão diferente da que se conhece hoje, pois eram eles que teriam que se adaptar à escola e sua proposta de ensino. Esse processo já havia sido destacado na CF em seu artigo 206, inciso I que estabelece a "igualdade de condições de acesso e permanência na escola", como um dos princípios para o ensino e, garante, como dever do Estado, a oferta do Atendimento Educacional Especializado - AEE, preferencialmente na rede básica de ensino (art. 208) que até a referida década não existia o AEE.

Reforçando ao instituído pela CF destaca-se ainda a Lei de Diretrizes e Bases da Educação - LDB n 9394/96 que traz uma inovação com capítulo específico para a Educação Especial; o Estatuto da Criança e do Adolescente Lei no. 8.069/90 e os documentos como a Declaração Mundial de Educação para Todos (1990) e a Declaração de Salamanca (1994), todos indutores das atuais Políticas Públicas da Educação Inclusiva.

O Plano Nacional de Educação Lei no 13.005/2014 o qual em sua meta 4 define como objetivo:

Universalizar, para a população de 4 (quatro) a 17 (dezessete) anos com deficiência, transtornos globais do desenvolvimento e altas habilidades ou superdotação, o acesso à educação básica e ao atendimento educacional especializado, preferencialmente na rede regular de ensino, com a garantia de sistema educacional inclusivo, de salas de recursos multifuncionais, classes, escolas ou serviços especializados, públicos ou conveniados. (BRASIL, 2014)

A meta da Educação Inclusiva apresenta ainda dezenove (19) estratégias que fomentam o alcance da mesma, representando ações que os municípios e os estados devem realizar de forma colaborativa dentro de seus respectivos planos.

Historicamente os surdos sofreram com a discriminação, tidos como inaptos e incapazes, vivendo sem quaisquer garantias de direitos até 1857, pela visão de superioridade da população falante, conforme aponta Capovilla (1997), pregava-se a ideia de que era impossível se comunicar de outra forma que não fosse oralmente, descartando-se assim outras formas de linguagem. 
Nesse enfoque Duboc (2004) afirma que, a história do processo de escolarização dessas pessoas perpassa primeiramente pela situação de que sua existência foi negligenciada por anos, com a exclusão do convívio social ou, por uma vida limitada ao assistencialismo, tendo a surdez como simples deficiência.

No Brasil a invisibilidade da população de surdos começou a diminuir quando Dom Pedro II convidou o professor Hernest Huet para criar a primeira escola de educação de meninos surdos, atualmente Instituto Nacional de Educação de Surdos (INES), em 26 de setembro de 1857, data oficializada como o Dia do Surdo.

A busca pela efetivação de políticas públicas para o reconhecimento da língua de sinais mobilizou os movimentos sociais. Outro passo importante foi em relação às meninas, que tiveram um acesso mais tardio à educação, somente no início do século XX que as mesmas foram admitidas no Instituto Santa Terezinha, situado em São Paulo. Onde se organizavam conforme a filosofia bilíngue, e tem como objetivo principal o desenvolvimento cognitivolinguístico, tendo acesso às duas línguas: a língua de sinais e o Português escrito.

Em relação às Filosofias Educacionais para a Educação de surdos podese dizer que em 1911 no Brasil por determinação do Congresso de Milão (1880), o INES estabeleceu o oralismo como método de educação dos surdos, que de acordo com as autoras Perlin e Strobel (2006), a proibição da Língua de Sinais no ano de 1880, resultou na abordagem do método de comunicação oralista, que compreendia o surdo com leitor de lábios e que deveria se expressar através do treino da fala - (Leitura dos lábios de quem está falando).

A Filosofia da Comunicação Total chega ao Brasil no final da década de 70 resultante da junção da Língua Oral com a Língua de Sinais. Com as pesquisas da Professora de Linguística Lucinda Ferreira Brito, em 1980 sobre a Língua Brasileira de Sinais - Libras começa a ganhar força no país a filosofia do bilinguismo (GOLDFELD, 1997). Esse pensamento se fortalece baseandose no aprendizado da Libras como primeira Língua do Surdo, onde a criança surda é ensinada por adultos surdos para posteriormente aprender a Língua Portuguesa na modalidade escrita.

Diferente da filosofia da Comunicação Total - que embora fizesse uso de uma série de recursos linguísticos e facilitadores para a comunicação entre os surdos e destes para com os ouvintes, esse modelo ainda mantinha a hegemonia do Oralismo - o bilinguismo, fortalece as comunidades surdas, principalmente quanto a afirmação da identidade cultural e visibilidade social, outro aspecto bastante importante nesta filosofia do bilinguismo é 0 empoderamento linguístico, tendo a Língua de Sinais como primeira língua no processo de ensino aprendizagem do aluno com surdez.

A Comunicação Total - que tem como preocupação os processos comunicativos e a aprendizagem, revela-se como uma ponte evolutiva entre o Oralismo e o Bilinguismo. E esta mudança de modelo possibilita a comunidade surda a oportunidade de ouvir e ser ouvida tendo a língua de sinais como prioridade linguística na comunicação, de maneira representativa em face das discussões oralistas.

Considerando - dentro da filosofia do bilinguismo - que a Língua de Sinais e a Língua Escrita fazem parte da rotina escolar do aluno com surdez e não 
surdo, torná-las comum entre os envolvidos no processo educacional, representa uma conquista histórica, e importante mudança de paradigma.

Ainda sobre o Bilinguismo destaca-se que primeiro os surdos adquirem a Língua de Sinais (LS) e depois aprendem o Português na modalidade escrita, o que segundo Alves (2015) é explicado por Quadros (1997, 2006), Góes (1999), Skliar (1997), Schubert (2015) e Fernandes (2005), que não trata-se somente de tornar disponível o uso de duas línguas no contexto escolar, "tomando a LS uma língua natural e a Portuguesa uma segunda língua", é garantir a equidade e igualdade.

É notório que tais metodologias vão se transformando conforme as pesquisas e discussões no rol das políticas públicas, pois impulsiona os governos a preocuparem com a questão, pois,

A comunidade surda veio conquistando seu espaço na sociedade. Hoje, os governos têm preocupado com a educação dos surdos, sendo esses inclusos no conceito de necessidades educacionais especiais expresso na Declaração de Salamanca que evoca linhas de ações especificas buscando reconhecer as diferenças, entre elas, a educação de surdos, considerando uma das peculiaridades da educação de surdos: a língua (FELIPE, 2001, p. 15).

Skliar (1997) alerta também de que o que se torna emergente são as mudanças de concepção do sujeito surdo, as descrições em torno da sua língua, as definições sobre políticas educacionais, a análise das relações de poder entre surdos e ouvintes.

A transição da Educação dos surdos de clínica assistencialista, para de pessoas dotadas de capacidade de aprender enfrentou e continua enfrentando muitos obstáculos, porém as conquistas deram novas perspectivas para o avanço das tendências e filosofias educacionais.

Assim, a Língua Brasileira de Sinais - Libras foi reconhecida legalmente como primeira língua da comunidade de surdos em 24 de abril de 2002 através da Lei $n^{\circ} 10.436$ e do decreto $n^{\circ} 5.626$, de 22 de dezembro de 2005 que a regulamenta. Compreende-se, assim, por Libras:

[...] forma de comunicação e expressão, em que o sistema linguístico de natureza visual-motora, com estrutura gramatical própria, constituem um sistema linguístico de transmissão de ideias e fatos, oriundos de comunidades de pessoas surdas do Brasil. (BRASIL, Lei № 10.436, 2002).

Esse reconhecimento representou um progresso significativo, contudo, foi apenas em 2005, que de fato esta Lei foi regulamentada pelo Decreto $\mathrm{n}^{\circ}$ $5.626 / 05$, que em seu artigo $2^{\circ}$ explana que "considera-se pessoa surda aquela que, por ter perda auditiva, compreende e interage com o mundo por meio de experiências visuais, manifestando sua cultura principalmente pelo uso da Língua Brasileira de Sinais - Libras".

A Libras é, portanto, uma língua, que assim como demais línguas conhecidas, apresenta seus próprios aspectos gramaticais, como enfatiza Gesser (2009, p. 27) "linguisticamente, pode-se afirmar que a língua de sinais é 
língua porque apresenta características presentes em outras línguas naturais e, essencialmente, por que é humana". Então, é necessário desmitificar a ideia de Libras como mímicas, e entende-la não apenas como linguagem, mas como uma língua que abrange uma comunicação eficaz, e portanto, para que seja também ensinada precisa estar inserida no currículo do curso de formação de professores do ensino básico. Sobre esse tema, o Decreto no 5.626/05, em seu artigo $3^{\circ}$, estabeleceu que:

Art. 3ำ A Libras deve ser inserida como disciplina curricular obrigatória nos cursos de formação de professores para 0 exercício do magistério, em nível médio e superior, e nos cursos de Fonoaudiologia, de instituições de ensino, públicas e privadas, do sistema federal de ensino e dos sistemas de ensino dos Estados, do Distrito Federal e dos Municípios.

$\S 10$ Todos os cursos de licenciatura, nas diferentes áreas do conhecimento, o curso normal de nível médio, o curso normal superior, o curso de Pedagogia e o curso de Educação Especial são considerados cursos de formação de professores e profissionais da educação para o exercício do magistério.

$\S 20$ A Libras constituir-se-á em disciplina curricular optativa nos demais cursos de educação superior e na educação profissional, a partir de um ano da publicação deste Decreto.

Contudo, ainda que os cursos de formação inicial tenham a Libras como disciplina obrigatória, isso não garante que os docentes se tornem fluentes em Libras ao ponto de não mais depender do profissional tradutor intérprete de Língua de Sinais (TILS) em sala para se comunicar diretamente com o aluno surdo. Reforça-se aí a necessidade de uma formação docente em Libras, para compreender os processos de aprendizagem do aluno surdo.

Ao conhecer o processo educacional de um aluno surdo é possível analisar os métodos de ensino aplicados e sua eficácia em estimular, além de potencializar a aprendizagem do surdo em seus métodos educativos. A respeito da importância de identificar e reafirmar mecanismos efetivos para a inclusão do surdo, Filietaz (2006, p. 02) assegura que para que isso corra no âmbito escolar seja reconhecida sua singularidade, "é assim que a educação inclusiva é importante, para uma sociedade plural e democrática que procura adaptar-se para recebê-lo e na qual os indivíduos aprendem a conviver e trabalhar com a diversidade."

Segundo Skliar (1997), a educação dos surdos ainda vem sendo marcada, ao longo da história, pelo fracasso escolar, justamente pelo fato de muitos docentes por falta de conhecimento, insistirem em tentar alfabetizar o aluno surdo não levando em consideração a sua especificidade em relação a língua de sinais e o português escrito.

Por isso, é necessário compreender que a língua materna do surdo é a Libras, possível de ser efetivada somente após o entendimento de que o bilinguismo, é o processo que torna acessíveis duas línguas no contexto escolar inclusivo, a língua de sinais que é considerada a Língua materna do surdo, e a língua oficial do país, a Língua Portuguesa, como segunda língua na modalidade escrita. 


\section{O processo de aprendizagem de alunos surdos tendo a Libras como mediadora}

A Libras é reconhecida em sua capacidade linguística como um meio plenamente eficaz para a comunicação do surdo. Visto que a partir da observação da comunicação utilizada pelos surdos para se expressarem foi possível compreender as concepções sociais e antropológicas vivenciadas pela Comunidade Surda e dessa forma difundir a língua de sinais como uma ferramenta essencial para o ensino de pessoas com surdez.

Ao conhecer o processo educacional de um aluno surdo é possível analisar os métodos de ensino aplicados e sua eficácia em estimular, além de potencializar a aprendizagem do surdo em seus métodos educativos, enfatizando o uso de recursos imagéticos para que o mesmo possa associar distintos conteúdo. Assim Lacerda, Santos e Caetano afirmam que:

A escola pode colaborar para a exploração das várias nuances da imagem, signo, significado e semiótica visual na prática educacional cotidiana, oferecendo subsídios para ampliar os "olhares" aos sujeitos Surdos e à sua capacidade de captar e compreender o "saber" e a "abstração" do pensamento imagético (LACERDA; SANTOS; CAETANO, 2011, p. 108).

O recurso visual é uma ferramenta importante que o professor deve explorar durante o processo de ensino aprendizagem do aluno surdo, para que o mesmo possa desenvolver-se e ampliar o seu conhecimento de mundo. Reafirmando a importância do uso de imagens Fernandes salienta que:

É sabido que é prioritariamente pela experiência visual que os surdos constroem conhecimento. Esse canal sensorial é a porta de entrada para o processamento cognitivo e deve ser explorado em todas as suas possibilidades, a fim de que elementos da realidade possam ser representados por símbolos visuais. (FERNANDES 2005, p. 33).

Consequentemente se o ensino básico adotar uma compreensão para as ações pedagógicas que fomentem a aprendizagem do indivíduo surdo, é indiscutível que este irá retirar-se da margem social contemplando todos os seus direitos e atribuições escolares, assim Nunes aborda que:

O conceito de educação inclusiva encontra-se em um limbo. Se por um lado avançamos no que se refere ao caráter de exceção presente na educação "especial", que diz respeito a uma condição especial, por outro, seu uso nos mostra que ainda nos distanciamos da educação democrática, pois o foco no "incluso" dá tanta luz a ele que denuncia uma inclusão ainda pela metade. (NUNES, 2015, p. 541)

Portanto, para que a educação inclusiva seja direcionada a aprendizagem a fim de apenas proporcionar ao surdo um convívio social escolar faz-se necessário analisar o papel desses agentes responsáveis pelo processo pedagógico em que estão inseridos, pois para Filietaz (2006, p. 02) "o conceito 
de inclusão pressupõe que a concentração de esforços, no sentido de fazer com que o processo inclusivo realmente ocorra em toda a sua amplitude"

Ao se tratar da inclusão do surdo no ensino básico é indispensável reafirmar a presença do TILS de Libras, como salienta Damázio que elucida que esse profissional:

É a pessoa que, sendo fluente em Língua Brasileira de Sinais e em Língua Portuguesa, tem a capacidade de verter em tempo real interpretação (Simultânea) ou, com um pequeno espaço de tempo (interpretação consecutiva), da Libras para o Português ou deste para a Libras. [...]. (DAMÁZIO, 2007, p. 49)

Diante desse personagem que é essencial para a interação e comunicação do aluno surdo com os demais membros da comunidade escolar, cabe ressaltar que o papel do TILS na sala de aula é apenas mediar a comunicação e não ministrar a aula para o aluno surdo. Por isso é importante que o professor também tenha conhecimento da Libras para que haja um diálogo direto com o aluno em relação a dúvidas a respeito do conteúdo das aulas que possam ser solucionadas pessoalmente, frente a frente com o aluno surdo. Pois deste modo o aluno poderá se sentir valorizado e convencido de que a sua língua materna é respeitada pelo educador. Logo, Perlin e Miranda (2011, p. 105) reforçam esta argumentação enfatizando que a respeito da qualificação do educador para "a formação de surdos seria melhor se os professores realmente entendessem de cultura surda e da facilidade do surdo adquirir conhecimento através dessa cultura."

Isso não desmerece e não desloca o TILS da sua função, pois continuaria sendo necessária a interpretação da aula ministrada em português para a Libras num contexto em que o professor esteja explanando para toda a turma por exemplo, pois não seria possível para o educador ministrar a aula em Libras e em português simultaneamente, bem como o TILS pode atuar em distintos momentos na escola.

Contudo Pimentel aponta que:

O reconhecimento das peculiaridades e diversidade do processo de aprendizagem; a percepção das potencialidades dos estudantes com deficiência de modo que possa planejar práticas pedagógicas que considerem as necessidades dos educandos, promovendo a adaptação do currículo escolar. (PIMENTEL, 2012, p. 152).

Além da formação adequada, compreende-se que esse educador que saiba a língua de sinais poderá desenvolver o seu planejamento pedagógico adequando-se às especificidades do aluno surdo, por isso Dorziat ressalta que:

A clareza sobre essas questões em torno da surdez pode influenciar significativamente nos encaminhamentos do trabalho pedagógico do professor. A prática ou como desenvolver as atividades em sala de aula tornar-se-á vazia e inócua, na medida em que não se tiver pontos de partida e pontos de chegada. (DORZIAT, 2011, p. 85). 
A comunicação do professor do ensino básico mediada pela Libras poderá promover um envolvimento maior do aluno surdo com os temas abordados no plano de aula, além disso reafirmar a participação e interação deste aluno em sala de aula, em parceria com o TILS que poderá conduzir a comunicação para a Libras. Assim Lacerda (2011, p. 177) salienta que "a presença de um TILS em sala de aula pode minimizar alguns aspectos desse problema, em geral, favorecendo uma melhor aprendizagem de conteúdos acadêmicos pelo aluno".

\section{Comunicação: os desafios na interação entre professor e aluno surdo no ensino básico.}

Com o avanço da ciência e tecnologia, e o surgimento de aparelhos auditivos. O milagre da ciência e os mecanismos facilitadores da vida moderna não foram suficientes para continuar negando a realidade surda na sociedade. O congresso de Milão (1880) seja talvez um dos momentos mais e difíceis e emblemático para a história de luta e reconhecimento da identidade cultural surda. Posteriormente, a imposição do oralismo, aos surdos, arrastou-se por mais de meio século ( $\mathrm{XIX}$ ao $\mathrm{XX}$ ) trazendo consequências retrógradas, mitigando a linguagem gestual à clandestinagem e aos redutos sombrios dos porões da sociedade.

Pensando na presença do surdo no ensino básico e nas relações a serem construídas dentro da escola, faz-se importante entender quem de fato é o surdo, em meio a tantas manifestações e graus de surdez diferentes que existem. No Decreto 5.626/2005, no seu Art.2o diz que:

Para os fins deste Decreto, considera-se pessoa surda aquela que, por ter perda auditiva, compreende e interage com o mundo por meio de experiências visuais, manifestando sua cultura principalmente pelo uso da Língua Brasileira de Sinais LIBRAS (BRASIL, 2005).

De acordo com a revista da Associação Brasileira de Psicologia Escolar e Educacional, a surdez é definida da seguinte forma:
A surdez é uma alteração no sistema auditivo e/ou nas vias auditivas que reduz ou impede o acesso aos estímulos sonoros. Tal alteração dependerá da localização da perda (ouvido médio, interno, unilateral, bilateral etc.); do momento da perda (antes ou depois da aquisição da linguagem, o que recebe o nome de surdez pré ou pós-lingual); e da intensidade da perda (leve, moderada, severa ou profunda) (NUNES; SAIA; SILVA; MIMESSI, 2015, p. 538).

Percebe-se que se há diferentes manifestações de surdez, também há diferentes concepções, destarte, a receptividade e as expectativas tendem a serem bastante relativas tanto em relação ao professor ouvinte quanto ao aluno surdo. Um aluno com experiência de surdez pré-natal, ou seja que já nasceu surdo, compreende a realidade bem diferente daquele aluno cuja surdez fora uma consequência pós-natal, que adquiriu a surdez posteriormente após ter 
experiência da audição ou resíduos auditivos distintos, e esta condição subsequente poderá se apresentar associada a um sentimento de perca, e frustações bem como questões interiores, no entanto, a autoestima e o entusiasmo continuam sendo valores imprescindíveis para o desenvolvimento de qualquer aluno independente da sua necessidade. Este é apenas um dos aspectos mais subjetivos que desafiam o professor a atender o aluno na sua especificidade.

Além da atuação do professor em sala de aula, a responsabilidade é compartilhada pela inclusão do aluno surdo no ensino básico com os demais membros da comunidade escolar. O espaço educacional escolar é por excelência oportuno e necessário, não sendo concebível negar esta prerrogativa que lhe é própria no tocante a valorização da dignidade humana e cidadania. Assim Martins diz que:

A escola não pode ficar presa a um modelo fechado, limitado apenas à tradução ou interpretação, mas sim estar aberta para as mais variadas forma de mediação simbólica ao universo surdo, onde eles possam ter oportunidades de uma construção conjunta de significações e de atribuição de sentidos àquilo que está à sua volta e aos conhecimentos que circulam nos espaços de interlocução. (MARTINS, 2010, p. 11).

Endossando um pouco mais para com os espaços escolares, o artigo 59 da LDB 9394/96 afirma que os sistemas de ensino devem oferecer aos educandos com necessidades educacionais especiais dentre outras coisas:

II- professores com especialização, bem como professores do ensino regular para atendimento especializado, bem como professores do ensino regular capacitados para a integração desses educandos nas classes comuns.

Dessa forma é perceptível um avanço significativo, quando observa-se o contexto histórico da educação dos surdos e o seu progresso, reafirmando a escola como um espaço de pessoas diferentes, que juntas podem vislumbrar o conhecimento e construir oportunidades em equidade, diante de inúmeras possibilidades em que a comunicação não é concebida como um impedimento.

Sob essa premissa nota-se que um dos desafios que educadores podem enfrentar na educação de pessoas surdas no ensino básico, incide sobre e principalmente a comunicação, seja pela limitação que pode ocorrer do professor em relação ao domínio e uso da Libras, seja pela delimitação e dependência do interprete em sala de aula. Outro fator também divergente, é a ausência do ensino de Libras para os alunos ouvintes, que possibilitaria para uma melhor interação e construção criativa de instrumentos de aprendizagem, a fim de favorecer a interação entre ambos os alunos surdos e ouvintes.

Partindo então do pressuposto de que [...] a dificuldade maior dos surdos está exatamente na aquisição de uma linguagem que subsidie seu desenvolvimento cognitivo, os estudos que envolvem a condição de pessoa surda são revestidos de fundamental importância e seriedade, visto que a surdez, analisada exclusivamente do ponto de vista do 
desenvolvimento físico, não é uma deficiência grave, mas a ausência da linguagem, além de criar dificuldades no relacionamento pessoal, acaba por impedir todo o desenvolvimento psicossocial do indivíduo. (SÁ, 1999, p. 47).

O estabelecimento de uma comunicação que possa viabilizar uma aproximação confiante e significativa e que cogite troca de experiências, apresenta-se como a primeira conquista propicie o acesso ao conhecimento e a tudo que é direito e digno à pessoa em si, e como sujeito social: comunicação! Isso ainda é o grande desafio para os educadores.

Assim, Goldfeld (2002), considera o surdo como uma pessoa que possui cultura, língua, forma de pensar e de agir próprias, e não como uma pessoa que não é capaz de escutar, ele avalia a surdez como uma oportunidade de aprendizagens mútuas e não um empecilho para a formação do aluno. Talvez o preconceito se estruture na concepção do que se entende como cultura. Strobel (2008, p. 30) afirma que "uma cultura é um conjunto de comportamentos apreendidos de um grupo de pessoas que possuem sua própria língua, valores, regras de comportamento e tradições".

Ainda é possível conjecturar que teremos "super professores" que consigam dentro da excelência, atender a todos, e em suas particularidades? Segundo Aranha (2004, p. 65), "escola inclusiva é aquela que garante a qualidade de ensino educacional a cada um de seus alunos, reconhecendo e respeitando a diversidade e respondendo a cada um de acordo com suas potencialidades e necessidades", por isso cabe salientar que a relação professor/aluno, sempre foi, a priori, um dos pontos mais importantes, para um bom desenvolvimento do trabalho educacional, quando falamos da relação professor e aluno surdo, essa interação é ressignificada, principalmente dada a desconfiança e insegurança criada pelas incógnitas das diferenças linguísticas ou simplesmente pela ausência de um contato direto quando não há a comunicação em Libras.

\section{PROCEDIMENTOS METODOLÓGICOS}

O autor Paulo Freire (2006, p. 29) já afirmou que "não há ensino sem pesquisa, nem pesquisa sem ensino", o ato de investigar, portanto, constitui-se em um conjunto de procedimentos que visam produzir um novo conhecimento e não reproduzir, simplesmente, o que já se sabe sobre um dado objeto em um determinado campo científico. Neste sentido, Antônio Carlos Gil (2008, p. 19) considera a pesquisa como: "Procedimento racional e sistemático que tem como objetivo proporcionar respostas aos problemas que são propostos".

Nesse processo de busca por respostas, o pesquisador dispõe de diferentes métodos que melhor contribuam para sua investigação, e na busca de atender aos objetivos propostos, e as do tempo encurtado da pesquisa, optou-se por uma abordagem de cunho bibliográfico, pois,

A pesquisa bibliográfica é feita a partir do levantamento de referências teóricas já analisadas, e publicadas por meios escritos e eletrônicos, como livros, artigos científicos, páginas de web sites. Qualquer trabalho científico inicia-se com uma pesquisa bibliográfica, que permite ao pesquisador conhecer 0 
que já se estudou sobre o assunto. Existem porém pesquisas científicas que se baseiam unicamente na pesquisa bibliográfica, procurando referências teóricas publicadas com o objetivo de recolher informações ou conhecimentos prévios sobre o problema a respeito do qual se procura a resposta (FONSECA, 2002, p. 32).

Considerando assim os estudos de pesquisadores e as publicações oficiais que abarcam os pressupostos da Educação Inclusiva, com foco na relação pedagógica entre o professor e o aluno surdo tendo a Libras como mediadora. Desta forma, o estudo bibliográfico possibilita confrontar ideias, conforme afirma Gil (2008, p. 44), "os exemplos mais característicos desse tipo de pesquisa são sobre investigações sobre ideologias ou aquelas que se propõem à análise das diversas posições acerca de um problema. "

\section{RESULTADOS E DISCUSSÃO}

Ao realizar o levantamento bibliográfico a fim de analisar a relação pedagógica entre o professor e o aluno surdo no ensino básico, tendo a Libras como mediadora, pode-se compreender que a comunicação entre o educador e o aluno surdo torna-se mais adequada e eficaz, com melhores resultados de aprendizagem quando o professor tem uma formação em Libras. Isso permite que as demandas idealizadas pela comunidade surda em relação ao contexto escolar sejam melhor compreendidas e atendidas. De acordo com Dorziat:

A iniciativa de garantia de entrada de todas as crianças na
escola é, sem dúvidas, importante, porque atende ao princípio
fundamental de direito de todos à educação. Entretanto, isso
não basta. Se não houver movimentos pedagógicos que se
debrucem sobre o aluno real, sobre suas formas de
representação, criando espaços de diálogo entre eles estar-se-
á promovendo outros tipos de exclusão (DORZIAT, 2011, p.
28).

Para isso é imprescindível que o professor tenha um olhar singularizado para o desenvolvimento do seu plano pedagógico, para que o aluno surdo participe efetivamente de todas as etapas da aula, com as mesmas oportunidades de interagir utilizando a língua de sinais como a língua materna e o português escrito como segunda língua. Por isso torna-se relevante e pertinente quando o profissional se antecipa ao sistema educacional, buscando a formação adequada em Libras para receber um aluno surdo antes mesmo da sua matrícula, sendo essa a conduta ideal que deve ser estimulada, visto que a pessoa com surdez pode estar presente em todas as modalidades de ensino. Logo Duboc explana que sobre uma particularidade em que,

O aluno surdo não pode ter sua identidade surda explicita a partir de um padrão universal, mas sim como formas plurais, dinâmicas, formadas e transformadas continuamente através das quais são representadas nos diferentes espaços sociais (DUBOC, 2004, p. 121). 
A Libras é uma língua gestual, cuja comunicação singular pode ser acompanhada de recursos imagéticos no processo de ensino aprendizagem como uma ferramenta que possibilite ao surdo compreender conceitos e temáticas apresentadas em sala de aula, fomentando assim a participação do surdo e ampliando as possibilidades de que o surdo obtenha sucesso no âmbito escolar. Nesse contexto Kelman (2011, p. 3609) destaca que "o ensino de alunos surdos apoia-se em duas vertentes, o bilinguismo e o uso de recursos especiais, baseados na experiência visual".

O estreitamento da comunicação entre professor e aluno surdo por meio da Libras é de suma importância para o desenvolvimento escolar do educando. Isto se deve a possibilidade de aumentar a crença subjetiva do aluno de pertencimento ao ambiente escolar na sua individualidade. Dessa forma Favaro e David relatam que:

[...] são importantes para a criança com surdez, que faz o uso das imagens para significar. No qual a criança começa a usar símbolos que têm importância para ela. Depois, passa a utilizar símbolos para que algumas pessoas possam compreender 0 que quer transmitir. (FAVARO; DAVID, 2012, p. 21)

Para que isso ocorra satisfatoriamente todos os membros da comunidade escolar precisam estar empenhados para romper as barreiras que dificultam a inclusão do surdo na escola além de amenizar os obstáculos referentes a comunicação que é fundamental entre o professor e o aluno surdo. A mudança de conceito implica mudança de paradigma, e quando olhamos para os desafios do educador junto ao seu educando surdo, não estamos falando apenas da escolarização, da transmissão de conteúdos curriculares como cumprimento de ementas e obrigações profissionais de ofício mas de uma educação inclusiva e igualitária no que tange à pessoa surda, que ainda tem na comunicação o seu maior desafio e impasse a serem superados.

\section{CONSIDERAÇÕES FINAIS}

Considerando a Libras como um sistema linguístico de transmissão de ideias e que instituem plenamente a comunicação de seus interlocutores, podese analisar que a interação entre aluno surdo e professor no âmbito escolar deve ser motivada pela prática educacional inclusiva cuja finalidade é promover a equidade e o desenvolvimento deste aluno. Partindo deste pressuposto, o desafio para que isso se concretize é a valorização do ato de ensinar estimulando uma comunicação plena em língua de sinais.

Para isso o uso de estratégias que possam envolver o aluno surdo deve ser explorado pelo professor no ensino básico, em especial os recursos imagéticos que poderão ampliar a visão de mundo deste aluno em relação a um dado especifico abordado em sala de aula. Mesmo diante dos avanços históricos, e as garantias legais conquistadas, as prerrogativas da supremacia ouvinte, seja pela ideia de fuga da realidade surda, recorrendo a paliativos migratórios, seja pela dificuldade em reconhecer a identidade cultural de uma comunidade cuja língua que é própria e diferente, o aluno surdo poderá deparar-se com inúmeros desafios. Nesse momento o professor deve se 
aproximar do aluno a fim de que o mesmo possa se sentir pertencente ao espaço escolar e valorizado na sua especificidade, responsabilidade esta que se estende para toda comunidade escolar. O TILS possui um papel singular nesse contexto que é promover a sociabilidade desse aluno por meio da tradução em Libras, que é indispensável para inclusão, bem como a formação do professor do ensino básico que deve contemplar a Libras para que assim possa amenizar a possibilidade do fracasso durante o processo de ensino aprendizagem sendo eficiente para a comunicação expressiva com o aluno surdo e desenvolvimento cognitivo e social do mesmo.

Quando se pensa em espaços escolares trabalhando com alunos surdos em meio aos demais alunos ouvintes, entende-se que uma série de mudanças serão necessárias para que esta inclusão seja real. Passando por adaptações físicas e curriculares, metodologias que contemple a especificidade deste aluno, e o desafio de desenvolver atividades que promova a interação, e garanta uma aprendizagem sem prejuízos quando comparado aos ouvintes. E em tudo isso a Comunicação é o carro chefe! "A comunicação é um fator fundamental para o ser humano e LIBRAS é uma ferramenta que possibilita a interação dos surdos" (PORTAL EDUCAÇÃO, 2013).

Entre os desafios a serem superados estão a indiferença que finda por isolar o aluno dentro da escola, e o preconceito que o rotula com estereótipos. A desconstrução de paradigmas de inferioridade, seguida de uma valorização cultural e linguística que coloque a pessoa com surdez em equidade para com os ouvintes. E pensando na importância da relação entre professor e aluno surdo, a proximidade entre estes mediada por uma comunicação direta faz toda a diferença. Embora o professor seja ainda um dos personagens significativos neste processo, a construção de uma realidade não mais pautada em "armengues", mas fortalecida, valorizada e empenhada por um projeto escolar, que envolva toda a comunidade, dará um salto expressivo de um ideário filosófico para uma realidade de sucesso educacional e promoção humana.

Ainda é preciso avançar muito para que a relação professor e aluno com surdez dentro de uma escola de educação básica alcance resultados satisfatórios, mas o caminho do bilinguismo representa uma direção mais acertada, entendendo que a comunicação é a porta que se abre para o conhecimento humano e desenvolvimento social. Embora os desafios sejam grandes para os professores, experiências e pesquisas apontam para a importância de se trabalhar com a comunidade escolar a superação de impasses e ensaiar benesses comuns e dignas para todos.

\section{REFERÊNCIAS}

ALVES, FC. et al. Educação de surdos em nível superior: desafios vivenciados nos espaços acadêmicos. In: ALMEIDA, WG., org. Educação de surdos: formação, estratégias e prática docente [online]. Ilhéus, BA: Editus, 2015, pp. 27-47. ISBN 978-85-7455-445-7.

ARANHA, M. S. F. Educação inclusiva: transformação social ou retórica? In: OMOTE, S. Inclusão: intenção e realidade. Marília, SP: Fundepe Publicações, 2004. 
BRASIL. Ministério da Educação. Secretaria de Educação Especial. Lei №. 10.436, de 24 de abril de 2002. Dispõe sobre a Língua Brasileira de Sinais LIBRAS e dá outras providências.

BRASIL. A Educação Especial na Perspectiva da Inclusão Escolar: abordagem bilíngue na escolarização de pessoas com surdez. Brasília: Ministério da Educação, Secretaria de Educação Especial. 2010.

BRASIL. Lei no 13.146 de 6 de Julho de 2015. Institui a Lei Brasileira de Inclusão da Pessoa com Deficiência (Estatuto da Pessoa com Deficiência).

BRASIL. Constituição da República Federativa do Brasil. Brasília: Imprensa Oficial, 1988.

BRASIL. Ministério da Educação. Lei de Diretrizes e Bases da Educação Nacional, LDB 9.394, de 20 de dezembro de 1996.

BRASIL. Decreto no. 5.626, de 22 de dezembro de 2005. Regulamenta a lei № 10.436, que dispõe sobre a Língua Brasileira de Sinais - Libras, e o artigo 18 da Lei no 10.098, de 19 de dezembro de 2000. Disponível em: http://portal.mec.gov.br/seesp/arquivos/pdf/dec5626.pdf.

BRASIL. Ministério da Educação. Secretaria de Educação Especial. Política Nacional de Educação Especial na Perspectiva da Educação Inclusiva. Documento elaborado pelo Grupo de Trabalho nomeado pela Portaria Ministerial $n^{\circ} 555$, de 5 de junho de 2007, prorrogada pela Portaria $n^{\circ}$ 948, de 09 de outubro de 2007. Brasília, DF. MEC/SEESP, 2007.

CAPOVILLA, Fernando. Filosofias educacionais em surdez: oralismo, comunicação total e bilinguismo. In: Ciência cognitiva: teoria, pesquisa e aplicação, v. 1, n. 2, 1997. p. 561-588. Disponível em:

<http://www.portaleducacao.com.br/pedagogia/artigos/41273/importancia-dointerprete-delibras > Acessado em: 09 de agosto 2019.

DAMÁZIO, M. F. M. Atendimento Educacional Especializado - pessoas com surdez. Brasília: Ministério da Educação, Secretaria de Educação Especial. 2007

DORZIAT, A. Estudos surdos: diferentes olhares. Porto Alegre: Mediação, 2011.

DUBOC, M. J. O. A formação do professor e a inclusão educativa: uma reflexão centrada no aluno surdo. Sitientibus, Feira de Santana, n. 31, p. 119-130, 2004. 
FAVARO, B. A.; DAVID, D. E. H. Histórias infantis como enriquecimento linguístico para crianças com surdez na educação infantil. Curitiba: SEED, 2012.

FELIPE, Tâny. A. LIBRAS em contexto: curso básico. Livro do estudante. Brasília, Ministério da Educação/Secretaria de Educação Especial, 2001.

FERNANDES, Eulália. Surdez e bilinguismo. Porto Alegre: Mediação, 2005.

FILIETAZ, Marta Rejane Proença. Políticas públicas de educação Inclusiva: das normas à qualidade de formação do intérprete de língua de Sinais. Dissertação (Mestrado em Educação). Universidade Tuiuti do Paraná, 2006.

FONSECA, J. J. S. Metodologia da pesquisa científica. Fortaleza: UEC, 2002.

FORMOZO, Daniele de Paula. Currículo e educação de surdos. Dissertação (Mestrado em Educação), Universidade Federal de Pelotas, 2008. Disponível em: http://livros01.livrosgratis.com.br/cp064986.pdf

FREIRE. A importância do ato de ler: em três artigos que se completam. São Paulo: Cortez, 2006, p.25-30.

GESSER, Audrei. LIBRAS? Que língua é essa? Crenças e preconceitos em torno da língua de sinais e da realidade surda. São Paulo: Parábola Editorial, 2009.

GIL, Antônio Carlos. Como elaborar projetos de pesquisa. 5. ed. São Paulo: Atlas, 2008, p. 41.

GIL, Antônio Carlos. Métodos e técnicas de pesquisa social. 5. ed. São Paulo: Atlas, 1999. Como elaborar projetos de pesquisa, 4. ed. São Paulo: Atlas, 2002.

GOLDFELD, Marcia. A criança surda: Linguagem e cognição numa perspectiva sócio interacionista. São Paulo: Plexus, 1997.

GOLDFELD, Marcia. A criança surda: linguagem e cognição numa perspectiva sociointeracionista/ Marcia Godfield. - 5a Ed. - São Paulo: Plexus Editora, 2002.

KELMAN, C. A. Significação e aprendizagem do aluno surdo. In: Albertina Mitjáns-Martinez; Maria Carmen Villela Rosa Tacca. (Org.). Possibilidades de aprendizagem: ações pedagógicas para alunos com dificuldades e deficiências. 1를. Campinas: Alinea, 2011. 
LACERDA, C. B. F. de.; SANTOS, L. F.; CAETANO, J. F. Estratégias metodológicas para o ensino de alunos surdos. In: Língua brasileira de sinais: libras uma introdução. São Paulo: UAB-UFSCar, p. 103-118, 2011.

LACERDA, C. B. F. A inserção da criança surda em classe de crianças ouvintes: focalizando a organização do trabalho pedagógico. In: REUNIÃO ANUAL DA ANPED, 23, 2000, Caxambú.

LOPES, Maura Corcini. Surdez \& Educação. Belo Horizonte: Autêntica, 2007.

MARTINS, M. A. Lopes. Relação professor surdo / alunos surdos em sala de aula: análise das práticas bilíngues e suas problematizações. Piracicaba, SP: UNIMEP, 2010.

MIRANDA, Ana Patrícia e Silva de; FIGUEIREDO, Daiane Pinheiro; LOBATO, Huber Kline Guedes. A tecnologia da informação e comunicação e ensinoaprendizagem de alunos surdos: relato sobre a experiência de uma professora da sala de informática. In: diálogos sobre inclusão escolar e ensinoaprendizagem da libras e língua portuguesa como segunda língua para surdos. 2016

M.; TACCA, M. C. V. R. (Orgs.) Possibilidades de aprendizagem: ações pedagógicas para alunos com dificuldade e deficiência. Campinas: Unix, 2011.

NASCIMENTO, R. Pereira do. Preparando professores para promover a inclusão de alunos com necessidades educacionais especiais. Londrina, Paraná: Caderno Temático do Programa de Desenvolvimento Educacional PDE, 2008.

NUNES, Sylvia da Silveira; SAIA, Ana Lúcia; SILVA, Larissa Jorge; MIMESSI, Soraya D'Angelo. Surdez e educação: escolas inclusivas e/ou bilíngues? 2015. Disponível em: http://www.scielo.br/pdf/pee/v19n3/2175-3539-pee-19-0300537.pdf

PERLIN, G.; STROBEL, K. História cultural dos surdos: desafio contemporâneo. Educar em Revista, Curitiba, Brasil, Edição Especial 2006.

PERLIN, G. T.; MIRANDA, W. A performatividade em educação de surdos. In: SÁ, N. R. L. de (Org.). Surdos: qual escola? Manaus: Valer e Edua, 2011.

PIMENTEL, S. C. Formação de professores para a inclusão: saberes necessários e percursos formativos. In: MIRANDA, T. G.; FILHO, T, A. G. (Org.). O professor e a educação inclusiva: formação, práticas e lugares. Salvador: EDUFBA, 2012.

PORTAL EDUCAÇÃO. Importância do Intérprete de Libras, mar.2013. Disponível em: 
$<$ https://www.portaleducacao.com.br/conteudo/artigos/biologia/importancia-dointerprete-de-libras/41273>. Acesso em: 02 jul. 2019.

QUADROS, Ronice Muller de. Educação de surdos: aquisição da linguagem. Porto Alegre: Artes Médicas, 2006.

QUADROS, Ronice Muller de. 0 tradutor e intérprete de língua brasileira de sinais e língua portuguesa. Brasília: MEC; SEESP; Programa Nacional de Apoio a Educação de Surdos, 2003.

SÁ, Nídia R. L. Educação de Surdos: a caminho do bilingüismo. Niterói: EduFF, 1999. p. 47.

SKLIAR, Carlos. A educação dos surdos: una reconstrução histórica, cognitiva e pedagógica. Mendonça: EDIUNC, 1997.

SCHUBERT, S.E de M. Entre a Surdez e a Língua: Outros sujeitos... Novas relações (intérpretes e surdos desvelando sentidos e significados). Curitiba. Editora Prismas, 2015

STROBEL, Karen. As imagens do outro sobre a cultura surda. 2. ed. Florianópolis: UFSC, 2008. 